\title{
RESEARCH
}

Open Access

\section{Impact of intramuscular adipose tissue content on short- and long-term outcomes of hepatectomy for colorectal liver metastasis: a retrospective analysis}

Nobutoshi Horii, Yu Sawda, Takafumi Kumamoto, Nobuhiro Tsuchiya, Takashi Murakami, Yasuhiro Yabushita, Yuki Honma, Ryusei Matsuyama, Daisuke Morioka, Hirotoshi Akiyama and Itaru Endo*

\begin{abstract}
Background: Numerous reports regarding sarcopenia have focused on the quantity of skeletal muscle. In contrast, the impact of the quality of skeletal muscle has not been well investigated.

Methods: A retrospective analysis of 115 patients who underwent initial hepatectomy for colorectal liver metastasis between January 2009 and December 2016 in our hospital was performed. Intramuscular adipose tissue content (IMAC) was used to evaluate the quality of skeletal muscle by analysing computed tomography (CT) images at the level of the umbilicus. The impact of poor skeletal muscle quality on short-term and long-term outcomes after hepatectomy for colorectal liver metastasis was analysed.

Results: Patients were divided into two groups (high IMAC and normal IMAC) according to their IMAC values, and their backgrounds were compared. There were no significant differences in most factors between the two groups. However, both body mass index $(P=0.030)$ and the incidence of postoperative complications of Clavien-Dindo grade 3 or worse $(P=0.008)$ were significantly higher in the high-IMAC group. In multivariate analyses, an operative blood loss $>600 \mathrm{ml}(P=0.006)$ and high IMAC $(P=0.008)$ were associated with postoperative complications of Clavien-Dindo grade 3 or worse. Overall survival and recurrence-free survival were significantly lower $(P<0.001$ and $P=0.045$, respectively) in the high-IMAC group than in the normal IMAC group. In multivariate analyses for poor overall survival, high IMAC was associated with poor overall survival $(P<0.001)$.
\end{abstract}

Conclusions: IMAC is a prognostic factor for poor short- and long-term outcomes in patients with colorectal liver metastasis.

Keywords: Colorectal cancer, Liver metastasis, Intramuscular adipose tissue content (IMAC), Sarcopenia, Prognostic factor

\footnotetext{
* Correspondence: endoit@yokohama-cu.ac.jp

Department of Gastroenterological Surgery, Yokohama City University, 3-9

Fukuura, Kanazawa-Ku, Yokohama 236-0004, Japan
}

(c) The Author(s). 2020 Open Access This article is licensed under a Creative Commons Attribution 4.0 International License, which permits use, sharing, adaptation, distribution and reproduction in any medium or format, as long as you give appropriate credit to the original author(s) and the source, provide a link to the Creative Commons licence, and indicate if changes were made. The images or other third party material in this article are included in the article's Creative Commons licence, unless indicated otherwise in a credit line to the material. If material is not included in the article's Creative Commons licence and your intended use is not permitted by statutory regulation or exceeds the permitted use, you will need to obtain permission directly from the copyright holder. To view a copy of this licence, visit http://creativecommons.org/licenses/by/4.0/ The Creative Commons Public Domain Dedication waiver (http://creativecommons.org/publicdomain/zero/1.0/) applies to the data made available in this article, unless otherwise stated in a credit line to the data. 


\section{Introduction}

The loss of skeletal muscle (sarcopenia) has been observed in various pathological conditions and is considered to be the result of various factors [1,2]. Sarcopenia has recently been reported to be a prognostic factor for poor short- and long-term outcomes in several cancers; these studies [3-8] assessed skeletal muscle mass using single-slice computed tomography (CT), but did not evaluate skeletal muscle quality.

To define sarcopenia, the strength and function of the skeletal muscle, in addition to muscle mass, must be evaluated. Changes in intramuscular adipose tissue (IMAT) with ageing have been reported to relate to weak and poor skeletal muscle function [7]. In addition, it has been reported that intramuscular adipose tissue content (IMAC), originally reported to be associated with the severity of nonalcoholic steatohepatitis (NASH), also reflects the quality of skeletal muscle $[9,10]$. Therefore, IMAC has attracted attention as a new parameter of sarcopenia. IMAC was associated with poor prognosis after living-donor transplantation [11] and after hepatectomy for hepatocellular carcinoma [12]. However, to the best of our knowledge, the clinical significance of IMAC in patients with colorectal liver metastasis (CRLM) has not been reported [13].

Colorectal cancer (CRC), one of the most common cancers, remains the main cause of death in Japan and worldwide [14]. Moreover, approximately $25 \%$ of colorectal cancer patients are reported to have liver metastasis upon diagnosis, and there is a high rate of recurrence after hepatectomy $[15,16]$. Hepatectomy is currently considered to be the most effective option for patients with liver metastases $[17,18]$.

Evaluating skeletal muscle area by $\mathrm{CT}$ imaging has been reported to be an inadequate method for assessing sarcopenia [12]. As CT imaging cannot distinguish muscle from adipose tissue, tissues with low muscle mass and high adipose tissue content could be deemed to have normal skeletal muscle area when measured by CT. In contrast, because IMAC reflects the quality of skeletal muscle, it has been suggested to be a better prognostic factor for sarcopenia in several diseases [12, 13]. However, there have been few studies on the utility of IMAC as a prognostic factor, and a significant association between CRLM and IMAC has not been reported.

In the present retrospective study, we evaluated skeletal muscle quality as reflected by IMAC as a new parameter of sarcopenia, with the aim of clarifying the relationship between IMAC and postoperative shortand long-term outcomes after hepatectomy for CRLM.

\section{Methods}

\section{Patients and methods}

The study used data for 189 patients who underwent initial hepatectomy for CRLM, from January 2009 to
December 2016, at the Yokohama City University Hospital. The following were excluded: 44 cases which required severe surgical invasion related to two-staged hepatectomy, 26 cases which lacked a CT image at the level of the umbilicus before surgery, and four cases for which a liver-first approach was performed. After exclusions, the medical records of the remaining 115 patients with CRLM were reviewed. This retrospective study was approved by the ethics committee of Yokohama City University (B190300006).

Hepatectomy was performed using a Cavitron Ultrasonic Surgical Aspirator (CUSA) and a bipolar cautery device equipped with a channel for water dripping. An intermittent Pringle manoeuvre and selective vascular clamping were utilized as necessary. Postoperative pathological diagnoses were performed to measure tumour size, tumour number, microvascular invasion, and tumour differentiation. All patients were followed up every 3 months after surgery, and tumour markers and CT scans were evaluated.

\section{Imaging analysis}

All CT imaging before surgery was performed with a multi-detector computed tomography scanner (Aquilion CXL and Aquilion PRIME, Canon Medical Systems, Otawara, Japan; SOMATOM Definition Flash, Siemens Healthcare, Forchheim, Germany). IMAC was calculated as follows: IMAC = region of interest (ROI) of the multifidus muscle (Hounsfield units)/ROI of subcutaneous fat (Hounsfield units) [12, 13].

On the preoperative plain $\mathrm{CT}$, the subfascial muscular tissues in the multifidus muscle were traced at the level of the umbilicus, and the CT values (in Hounsfield units) were calculated using the server in our hospital (Fig. 1a). $\mathrm{CT}$ values of the subcutaneous fat tissue were calculated using four circles traced on the subcutaneous fat area away from major vessels (Fig. 1a) at the level of the umbilicus. The average value of these four ROIs was defined as the ROI of the subcutaneous fat.

In general, IMAC tended to be a negative value. When the skeletal muscle contained more fat tissue, IMAC tended to be higher. Therefore, a higher IMAC value represents poorer skeletal muscle quality.

Skeletal muscle mass was evaluated using the psoas muscle index (PMI) at the level of the umbilicus. The bilateral psoas muscle area was evaluated using manual tracing (Fig. 1b). The PMI was calculated by normalizing these cross-sectional areas to height $\left(\mathrm{cm}^{2} / \mathrm{m}^{2}\right)[12,13]$.

In this study, due to the differences in the IMAC values of male and female patients, the cut-off point for each sex was set using a receiver operating characteristic curve (ROC curve).

The dependent variable was postoperative overall survival. The cut-off value was -0.335 for men and -0.258 

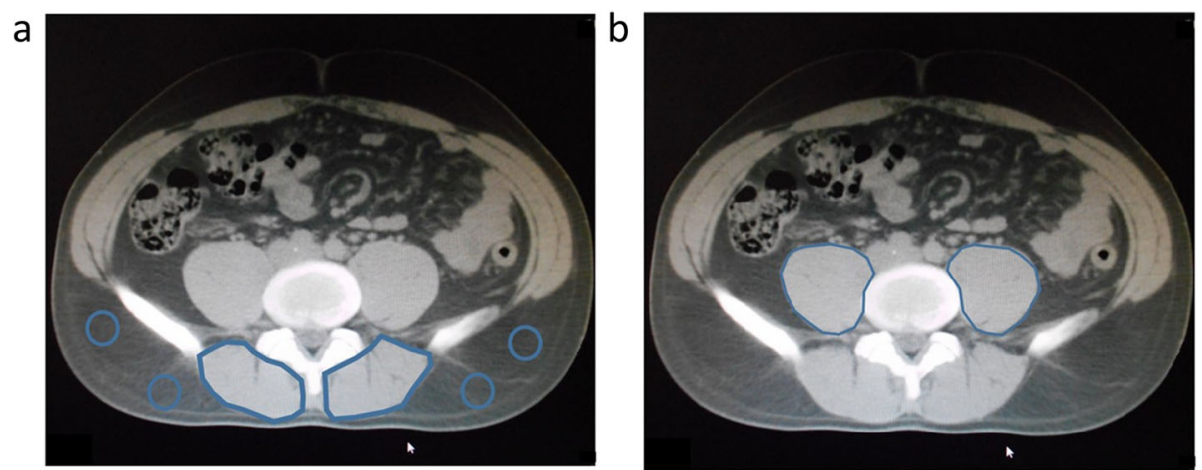

Fig. 1 a Cross-sectional computed tomography imaging of subcutaneous fat area and subfascial muscular tissue in multifidus muscle. b Bilateral psoas muscles at level of umbilicus

for women. Patients with a value higher than or equal to the cut-off value were classified in high-IMAC group $(\mathrm{H}$ group), and the remainder were classified in the normalIMAC group ( $\mathrm{N}$ group).

\section{Analysed parameters}

Overall survival rate $(\mathrm{OS})$ and recurrence-free survival rate (RFS) after hepatectomy for CRLM were evaluated for the patients classified according to IMAC. In addition, the following variables were analysed as prognostic factors: patient age, sex, body mass index (BMI), serum albumin, Onodera's prognostic nutritional index (PNI) [19], modified Glasgow prognostic score (mGPS) [20], American Society of Anesthesiologists Classification score (ASA score), PMI, carcinoembryonic antigen (CEA) level, serum carbohydrate antigen 19-9 (CA19-9) level, tumour size, number of tumours, tumour location, primary tumour location, surgical procedure, detection of metastasis at hepatectomy, operation time, operation bleeding, surgical margin as diagnosed by pathologists, perioperative chemotherapy, and the occurrence of postoperative complications. Postoperative complications were assessed using the Clavien-Dindo classification system [21, 22].

\section{Statistical analyses}

Values are presented as median (range) or number (percentage). Differences were assessed using MannWhitney $U$ tests for numerical variables and Fischer's exact probability tests for categorical variables. Survival was assessed using Kaplan-Meier life tables, and differences in survival were evaluated using Gehan-Breslow-Wilcoxon tests. A two-tailed $P$ value $(P)$ of $<0.05$ was considered significant. Statistical analyses were performed using SPSS commercial statistics software version 22 (IBM, Armonk, NY, USA).

\section{Results}

\section{Patient characteristics}

Baseline characteristics of the 115 patients in this study are summarized in Table 1. The median patient age was 67 years. Almost all patients had an ASA score of 1 or 2 . Twenty patients presented with metastasis to other organs at hepatectomy.

Comparisons between the IMAC $\mathrm{H}$ and $\mathrm{N}$ groups are shown in Table 2. BMI was significantly lower in the $\mathrm{N}$ group than in the $\mathrm{H}$ group $(P=0.030)$, but there were no significant differences in other tumour- and patientrelated factors. Moreover, postoperative complications (Clavien-Dindo grade 3 or worse) were significantly more frequent in the $\mathrm{H}$ group than in the $\mathrm{N}$ group (17.1\% vs. $1.9 \% ; P=0.011$ ). PMI, an indicator of skeletal muscle mass, was not significantly different between the two groups.

\section{Impacts of IMAC on postoperative complications}

As IMAC is considered to be associated with short-term prognosis, other risk factors for postoperative complications (Clavien-Dindo grade 3 or worse) were analysed. Univariate analysis and multivariate logistic regression analysis with backward elimination for postoperative complications of Clavien-Dindo grade 3 or worse are shown in Table 3.

In the univariate analysis, a tumour size $>30 \mathrm{~mm}$ $(P=0.046)$, operation time $>480 \mathrm{~min}(P=0.040)$, operative blood loss $>600 \mathrm{ml}(P=0.003)$, and the $\mathrm{H}$ group $(P=0.020)$ were significantly associated with a postoperative complication of Clavien-Dindo grade 3 or worse. The PMI cut-off values were set using an ROC curve, and patients with low PMI were classified as the low PMI group (PMI cut-offs: men, 6.0; women, 4.0). No significant association was found between postoperative complications and the low PMI group. 
Table 1 Patient characteristics in this study

\begin{tabular}{|c|c|}
\hline & Total $(n=115)$ \\
\hline \multicolumn{2}{|c|}{ Age at surgery (years) } \\
\hline Median (IQR) & $67(27-85)$ \\
\hline \multicolumn{2}{|l|}{ Gender, $n$ (\%) } \\
\hline Male & $79(69)$ \\
\hline Female & $36(31)$ \\
\hline \multicolumn{2}{|c|}{ Serum albumin level (g/dl) } \\
\hline Median (IQR) & $4.1(3.2-5.0)$ \\
\hline \multicolumn{2}{|l|}{ ASA score, $n(\%)$} \\
\hline 1 & $32(28)$ \\
\hline 2 & $75(65)$ \\
\hline 3 & $8(7)$ \\
\hline \multicolumn{2}{|l|}{ PNI } \\
\hline Median (IQR) & $47.7(35.9-59.2)$ \\
\hline \multicolumn{2}{|l|}{ CRP (mg/dl) } \\
\hline Median (IQR) & $0.90(0.01-4.24)$ \\
\hline mGPS, $n(\%)$ & 0 \\
\hline 0 & $93(81)$ \\
\hline 1 & $18(16)$ \\
\hline 2 & $4(3)$ \\
\hline \multicolumn{2}{|l|}{ BMl } \\
\hline Median (IQR) & $21.3(14.7-30.4)$ \\
\hline \multicolumn{2}{|c|}{ Primary tumour location, $n$ (\%) } \\
\hline Colon & $77(67)$ \\
\hline Rectum & $38(33)$ \\
\hline \multicolumn{2}{|c|}{ Tumour location, n (\%) } \\
\hline Unilobe & $16(14)$ \\
\hline Bilobe & $99(86)$ \\
\hline \multicolumn{2}{|c|}{ Tumour size (mm) } \\
\hline Median (IQR) & $28(5-120)$ \\
\hline \multicolumn{2}{|c|}{ Number of tumours } \\
\hline Median (IQR) & $3(1-30)$ \\
\hline \multicolumn{2}{|c|}{ Detection of metastasis, $n$ (\%) } \\
\hline Synchronous & $60(52)$ \\
\hline \multicolumn{2}{|l|}{ Metachronous } \\
\hline \multicolumn{2}{|l|}{ CEA (ng/dl) } \\
\hline Median (IQR) & $5.5(1.1-855)$ \\
\hline \multicolumn{2}{|l|}{ CA19-9 (mU/l) } \\
\hline Median (IQR) & $26(1-2368)$ \\
\hline \multicolumn{2}{|c|}{ Preoperative chemotherapy, n (\%) } \\
\hline Yes & $71(62)$ \\
\hline No & $44(38)$ \\
\hline \multicolumn{2}{|c|}{ Postoperative chemotherapy, $n$ (\%) } \\
\hline Yes & $48(42)$ \\
\hline No & $67(58)$ \\
\hline
\end{tabular}

Table 1 Patient characteristics in this study (Continued)

\begin{tabular}{ll}
\hline & Total $(n=115)$ \\
\hline Other organ metastasis at hepatectomy, $n(\%)$ & $20(17)$ \\
Yes & $21(18)$ \\
$\quad$ Positive & $94(82)$ \\
$\quad$ Negative & \\
Surgical procedure, $n$ (\%) & $34(30)$ \\
$\quad$ Major resection & $81(70)$ \\
$\quad$ Minor resection & \\
Synchronous resection for primary tumour, $n(\%)$ & $9(8)$ \\
$\quad$ Yes & \\
Operation time (min) & $431(198-797)$ \\
$\quad$ Median (IQR) & $524(0-2257)$ \\
Operative blood loss (ml) & \\
$\quad$ Median (IQR) & $20(17)$ \\
Postoperative complications, $n$ (\%) & $12(10)$ \\
Clavien-Dindo grade II & \\
Clavien-Dindo grade III or IV
\end{tabular}

ASA score American Society of Anesthesiologists classification score, BMI body mass index, CA19-9 carbohydrate antigen 19-9, CEA carcinoembryonic antigen, $C R P$ C-reactive protein, IQR interquartile range, $m G P S$ modified Glasgow prognostic score, $P N /$ prognostic nutritional index

\section{RFS after hepatectomy}

RFS after hepatectomy for CRLM was significantly lower in the IMAC $\mathrm{H}$ group than in the $\mathrm{N}$ group $(P=0.045$; Fig. 2a). Twenty patients had metastases to other organs and were excluded from this comparison.

\section{OS after hepatectomy for CRLM}

OS was significantly lower in the IMAC $\mathrm{H}$ group than in the $\mathrm{N}$ group $(P<0.001$; Fig. $2 \mathrm{~b})$. Moreover, when cases with metastasis from other organs at the time of hepatectomy were excluded, OS was significantly worse in the $\mathrm{H}$ group $(P=0.001$; Fig. $2 \mathrm{c})$.

We analysed several other prognostic factors for OS. The results of univariate analyses and multivariate analysis with backward elimination are summarized in Table 4 In univariate analyses, bilobed tumour $(P=$ $0.010)$, tumour size $>30 \mathrm{~mm}(P=0.009)$, number of tumours $>3(P=0.026)$, other-organ metastasis at hepatectomy $(P<0.001)$, CEA $>10 \mathrm{ng} / \mathrm{dl}(P=0.001)$, postoperative complications of Clavien-Dindo grade 3 or worse $(P<0.001)$, and the $\mathrm{H}$ group $(P<0.001)$ were significantly associated with poor OS. In the multivariate analysis, bilobed tumour $(P=0.002)$, other-organ metastasis $(P=0.001), \mathrm{CEA}>10 \mathrm{ng} / \mathrm{dl}(P=0.025)$, and the $\mathrm{H}$ group $(P<0.001)$ were associated with poor OS. As a high IMAC was associated with postoperative complications of Clavien-Dindo grade 3 or worse, postoperative 
Table 2 Comparison of patient backgrounds between normal and high IMAC groups

\begin{tabular}{|c|c|c|c|}
\hline & $\begin{array}{l}\text { H group } \\
(n=64)\end{array}$ & $\begin{array}{l}N \text { group } \\
(n=51)\end{array}$ & $P$ value \\
\hline \multicolumn{4}{|l|}{ Age (years) } \\
\hline Median (IQR) & $68(40-85)$ & $65(27-80)$ & 0.381 \\
\hline \multicolumn{4}{|l|}{ Gender, n (\%) } \\
\hline Male & $47(72)$ & $32(63)$ & 0.232 \\
\hline Female & $17(28)$ & $19(27)$ & \\
\hline \multicolumn{4}{|c|}{ Serum albumin level (g/dl) } \\
\hline Median (IQR) & $4.1(3.3-5.0)$ & $4.1(3.2-4.9)$ & 0.378 \\
\hline \multicolumn{4}{|l|}{ ASA score, $n(\%)$} \\
\hline 1 & $20(31)$ & $12(24)$ & 0.646 \\
\hline 2 & $40(63)$ & $35(68)$ & \\
\hline 3 & $4(6)$ & $4(8)$ & \\
\hline \multicolumn{4}{|l|}{$\mathrm{PNI}$} \\
\hline Median (IQR) & $47.2(38.7-58.3)$ & $49.4(35.9-59.2)$ & 0.113 \\
\hline \multicolumn{4}{|l|}{ CRP } \\
\hline Median (IQR) & $0.1(0.01-7.24)$ & $0.08(0.01-4.14)$ & 0.504 \\
\hline \multicolumn{4}{|l|}{ mGPS, $n(\%)$} \\
\hline 0 & $54(84)$ & $39(76)$ & 0.373 \\
\hline 1 & $9(14)$ & $9(18)$ & \\
\hline 2 & $1(2)$ & $3(6)$ & \\
\hline \multicolumn{4}{|l|}{ BMI } \\
\hline Median (IQR) & $21.9(14.7-30.4)$ & $20.7(16.1-27.4)$ & 0.030 \\
\hline \multicolumn{4}{|c|}{$\begin{array}{l}\text { Primary tumour location, } \\
n(\%)\end{array}$} \\
\hline Colon & $44(69)$ & $33(65)$ & 0.693 \\
\hline Rectum & $20(31)$ & $18(35)$ & \\
\hline \multicolumn{4}{|c|}{ Tumour location, $n$ (\%) } \\
\hline Unilobe & $30(47)$ & $19(27)$ & 0.345 \\
\hline Bilobe & $34(53)$ & $32(63)$ & \\
\hline \multicolumn{4}{|l|}{ Tumour size (mm) } \\
\hline Median (IQR) & $33.5(5-120)$ & $27(7-80)$ & 0.156 \\
\hline \multicolumn{4}{|c|}{ Number of tumours } \\
\hline Median (IQR) & $3(1-30)$ & $4(1-12)$ & 0.677 \\
\hline \multicolumn{4}{|c|}{$\begin{array}{l}\text { Detection of metastasis, } \\
n(\%)\end{array}$} \\
\hline Synchronous & $30(47)$ & $30(59)$ & 0.260 \\
\hline Metachronous & $34(53)$ & $21(41)$ & \\
\hline \multicolumn{4}{|l|}{ CEA (ng/dl) } \\
\hline Median (IQR) & $8.3(1.3-855)$ & $4.3(1.1-718)$ & 0.504 \\
\hline \multicolumn{4}{|l|}{ CA19-9 (mU/l) } \\
\hline Median (IQR) & $27(1-2368)$ & $14(1-984)$ & 0.477 \\
\hline \multicolumn{4}{|c|}{$\begin{array}{l}\text { Preoperative chemotherapy, } \\
n(\%)\end{array}$} \\
\hline Yes & $41(64)$ & $30(59)$ & 0.700 \\
\hline No & $23(36)$ & $21(41)$ & \\
\hline
\end{tabular}

Table 2 Comparison of patient backgrounds between normal and high IMAC groups (Continued)

\begin{tabular}{|c|c|c|c|}
\hline & $\begin{array}{l}\text { H group } \\
(n=64)\end{array}$ & $\begin{array}{l}N \text { group } \\
(n=51)\end{array}$ & $P$ value \\
\hline \multicolumn{4}{|c|}{$\begin{array}{l}\text { Postoperative chemotherapy, } \\
n(\%)\end{array}$} \\
\hline Yes & $24(38)$ & $24(47)$ & 0.302 \\
\hline No & $40(62)$ & $27(53)$ & \\
\hline \multicolumn{4}{|c|}{$\begin{array}{l}\text { Other organ metastasis, } \\
n(\%)\end{array}$} \\
\hline Yes & $11(17)$ & $9(17)$ & 1.000 \\
\hline \multicolumn{4}{|c|}{ Surgical margin, $n(\%)$} \\
\hline Yes & $12(18)$ & $9(18)$ & 1.000 \\
\hline No & $52(82)$ & $42(82)$ & \\
\hline \multicolumn{4}{|c|}{ Surgical procedure, $n(\%)$} \\
\hline Major resection & $20(39)$ & $14(28)$ & 0.686 \\
\hline Minor resection & $44(61)$ & $37(72)$ & \\
\hline \multicolumn{4}{|c|}{$\begin{array}{l}\text { Synchronous resection } \\
\text { for primary tumour }\end{array}$} \\
\hline Yes & $4(8)$ & $5(8)$ & 0.481 \\
\hline \multicolumn{4}{|l|}{ Operation time (min) } \\
\hline Median (IQR) & $427(198-783)$ & $432(229-797)$ & 0.934 \\
\hline \multicolumn{4}{|c|}{ Operative blood loss (ml) } \\
\hline Median (IQR) & $515(0-2257)$ & $526(10-1975)$ & 0.934 \\
\hline \multicolumn{4}{|l|}{ PMl } \\
\hline \multicolumn{4}{|l|}{ Median (IQR) } \\
\hline Male & $6.2(1.8-10.1)$ & $6.1(3.8-10.1)$ & 0.892 \\
\hline Female & $4.4(2.2-10.7)$ & $4.4(2.3-10.7)$ & 1.000 \\
\hline \multicolumn{4}{|c|}{$\begin{array}{l}\text { Post-op complication } \\
\geq \text { C-D grade } 2\end{array}$} \\
\hline Yes, $n(\%)$ & $20(31)$ & $12(23)$ & 0.407 \\
\hline \multicolumn{4}{|c|}{$\begin{array}{l}\text { Post-op complication } \\
\geq \text { C-D grade } 3\end{array}$} \\
\hline Yes, $n(\%)$ & $11(17)$ & $1(1.9)$ & 0.011 \\
\hline
\end{tabular}

ASA score American Society of Anesthesiologists classification score, BMI body mass index, CA19-9 carbohydrate antigen 19-9, CEA carcinoembryonic antigen, CRP C-reactive protein, IQR interquartile range, $m G P S$ modified Glasgow prognostic score, $P M I$ psoas muscle index, $P N I$ prognostic nutritional index, Post-op postoperative

complications were excluded in the multivariate analysis as confounding factors.

\section{Discussion}

Skeletal muscle loss (sarcopenia) has been identified as a prognostic factor for several malignant diseases [3-8]. However, many studies have focused only on skeletal muscle mass, as assessed by CT of skeletal muscle area. In contrast, insufficient attention has been given to the deterioration of muscle quality that is associated with muscle fat deposition [3-8]. 
Table 3 Odds ratios from univariate and multivariate analysis of postoperative complications of Clavien-Dindo grade 3 or worse

\begin{tabular}{|c|c|c|c|c|c|c|}
\hline & \multicolumn{3}{|l|}{ Univariate } & \multicolumn{3}{|l|}{ Multivariate } \\
\hline & Odds ratio & $95 \% \mathrm{Cl}$ & $P$ value & Odds ratio & $95 \% \mathrm{Cl}$ & $P$ value \\
\hline Age $\geq 70$ years & 1.125 & $0.334-3.787$ & 1.000 & & & \\
\hline Male & 1.414 & $0.359-5.669$ & 0.849 & & & \\
\hline ASA score 2 or 3 & 2.055 & $0.425-9.942$ & 0.362 & & & \\
\hline $\mathrm{PNI}<45$ & 1.040 & $0.261-4.143$ & 0.956 & & & \\
\hline mGPS 1 or 2 & 2.361 & $0.641-8.694$ & 0.186 & & & \\
\hline $\mathrm{BMI}<22 \mathrm{~kg} / \mathrm{m}^{2}$ & 0.472 & $0.140-1.590$ & 0.218 & & & \\
\hline Bilobed tumour & 1.552 & $0.439-5.480$ & 0.492 & & & \\
\hline Tumour size $\geq 30 \mathrm{~mm}$ & 3.717 & $0.951-14.53$ & 0.046 & 2.633 & $0.425-7.359$ & 0.203 \\
\hline Number of tumours $\geq 4$ & 0.327 & $0.084-1.277$ & 0.094 & & & \\
\hline Metachronous occurrence & 0.757 & $0.226-2.541$ & 0.652 & & & \\
\hline$C E A \geq 10 \mathrm{ng} / \mathrm{dl}$ & 1.512 & $0.456-5.013$ & 0.497 & & & \\
\hline CA19-9 $\geq 20 \mathrm{mU} / \mathrm{l}$ & 1.887 & $0.535-6.658$ & 0.318 & & & \\
\hline Major resection & 2.697 & $0.797-9.000$ & 0.101 & & & \\
\hline Synchronous resection for primary tumour & 1.008 & $0.123-9.460$ & 0.945 & & & \\
\hline Operation time $\geq 480 \mathrm{~min}$ & 3.407 & $1.002-11.583$ & 0.040 & 1.768 & $0.592-11.703$ & 0.433 \\
\hline Operative blood loss $>600 \mathrm{ml}$ & 8.205 & $1.708-39.420$ & 0.003 & 9.564 & $1.913-47.811$ & 0.006 \\
\hline H group & 10.377 & $1.292-83.337$ & 0.008 & 12.326 & $1.478-102.784$ & 0.020 \\
\hline Low PMl group & 0.504 & $0.129-1.974$ & 0.318 & & & \\
\hline
\end{tabular}

ASA score American Society of Anesthesiologists classification score, BMI body mass index, CA19-9 carbohydrate antigen 19-9, CEA carcinoembryonic antigen, CI confidence interval, $H$ group high intramuscular adipose tissue content group, $m G P S$ modified Glasgow prognostic score, $P M I$ psoas muscle index, $P N I$ prognostic nutritional index

The usefulness of IMAC in hepatectomy for hepatocellular carcinoma (HCC) has been reported [12]. Our study was therefore conducted to assess the possible usefulness of IMAC in CRLM patients undergoing hepatectomy. In HCC, chronic hepatitis often exists in the background liver, and progression of fibrosis has been observed in the background liver. On the other hand, patients with CRLM rarely have chronic hepatitis in the background liver, and HCC and CRLM are considered to be different. Therefore, we believe that our findingthat IMAC is useful for predicting the prognosis of CRLM-is novel. To the best of our knowledge, our study is the first to find a significant association between IMAC and short- and long-term prognosis in patients with CRLM.

The utility of IMAC for assessing CRLM outcomes has been investigated previously [13]; in contrast to our findings, that study found that IMAC did not have a statistically significant impact on short- and long-term outcomes. The patient background data in our study are comparable with the data used in the previous study [13], and many factors show no remarkable differences between that study and ours. However, our study may have included several patients who underwent more
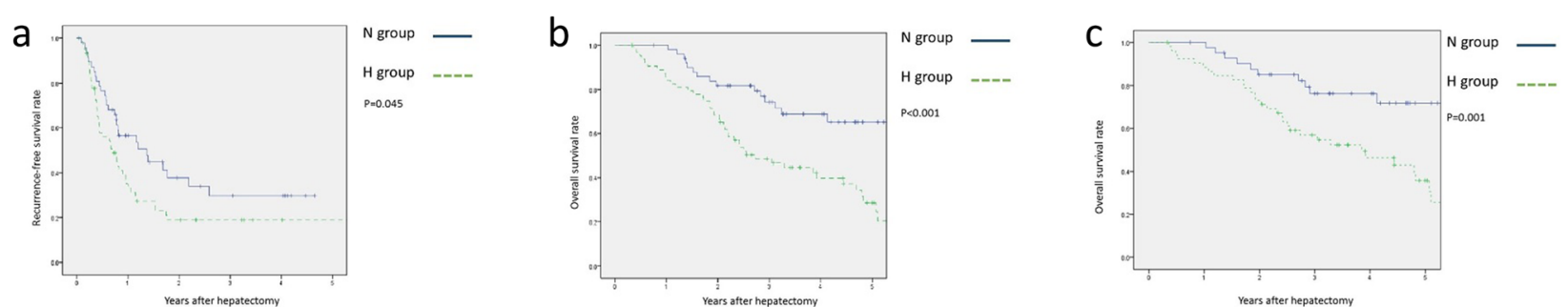

Fig. 2 Comparison of survival of patients with high and normal intramuscular adipose tissue content. a Recurrence-free survival. b Overall survival. c Overall survival, excluding cases with metastasis from other organs at the time of hepatectomy. $\mathrm{H}$ group: patients with high intramuscular adipose tissue content. $\mathrm{N}$ group: patients with normal intramuscular adipose tissue content 
Table 4 Univariate and multivariate analyses for overall survival

\begin{tabular}{|c|c|c|c|c|c|c|}
\hline & \multicolumn{3}{|c|}{ Univariate analysis } & \multicolumn{3}{|c|}{ Multivariate analysis } \\
\hline & Odds ratio & $95 \% \mathrm{Cl}$ & $P$ value & Odds ratio & $95 \% \mathrm{Cl}$ & $P$ value \\
\hline Age $\geq 70$ years & 0.864 & $0.506-1.478$ & 0.594 & & & \\
\hline Male & 1.328 & $0.746-2.363$ & 0.334 & & & \\
\hline ASA score 2 or 3 & 1.497 & $0.825-2.717$ & 0.181 & & & \\
\hline $\mathrm{PNI}<45$ & 1.167 & $0.639-2.130$ & 0.616 & & & \\
\hline mGPS 1 or 2 & 1.304 & $0.702-2.420$ & 0.399 & & & \\
\hline $\mathrm{BMI}<22 \mathrm{~kg} / \mathrm{m}^{2}$ & 0.612 & $0.364-1.030$ & 0.062 & & & \\
\hline Bilobe tumour & 2.039 & $1.176-3.535$ & 0.010 & 2.367 & $1.357-4.128$ & 0.002 \\
\hline Primary tumour rectum & 0.798 & $0.452-1.406$ & 0.433 & & & \\
\hline Tumour size $\geq 30 \mathrm{~mm}$ & 1.989 & $1.177-3.361$ & 0.009 & & & \\
\hline Number of tumours $\geq 4$ & 1.789 & $1.063-3.013$ & 0.026 & & & \\
\hline Metachronous & 1.003 & $0.597-1.684$ & 0.991 & & & \\
\hline Other organ metastasis at $\mathrm{Hx}$ & 2.714 & $1.518-4.855$ & $<0.001$ & 2.891 & $1.557-5.371$ & 0.001 \\
\hline Preoperative chemotherapy & 1.231 & $0.716-2.118$ & 0.452 & & & \\
\hline Postoperative chemotherapy & 0.698 & $0.408-1.194$ & 0.698 & & & \\
\hline$C E A \geq 10 \mathrm{ng} / \mathrm{dl}$ & 2.356 & $1.402-3.958$ & 0.001 & 1.838 & $1.078-3.133$ & 0.025 \\
\hline CA19-9 $\geq 20 \mathrm{mU} / \mathrm{l}$ & 1.578 & $0.928-2.684$ & 0.089 & & & \\
\hline Major resection & 1.306 & $0.746-2.286$ & 0.348 & & & \\
\hline Synchronous resection for primary tumour & 0.981 & $0.354-2.719$ & 0.970 & & & \\
\hline Operation time $\geq 480 \mathrm{~min}$ & 1.174 & $10.683-2.018$ & 0.562 & & & \\
\hline Operative blood loss $>600 \mathrm{ml}$ & 1.350 & $0.683-2.018$ & 0.254 & & & \\
\hline Po complication $\geq$ C-D grade 3 & 3.568 & $1.819-7.000$ & & & & \\
\hline H group & 2.842 & $1.577-5.123$ & $<0.001$ & 15.280 & $1.478-102.784$ & $<0.001$ \\
\hline Low PMl group & 0.850 & $0.497-1.453$ & 0.552 & & & \\
\hline
\end{tabular}

ASA score American Society of Anesthesiologists classification score, BMI body mass index, CA19-9 carbohydrate antigen 19-9, CEA carcinoembryonic antigen, CI confidence interval, $\mathrm{H}$ group high intramuscular adipose content group, $\mathrm{Hx}$ hepatectomy, mGPS modified Glasgow prognostic score, $P M I$ psoas muscle index, $P N I$ prognostic nutritional index, Po complication $\geq C-D$ grade 3 postoperative complication as Clavien-Dindo grade 3 or more severe

severe surgical invasion or were more advanced cases. These differences may have contributed to the statistical significance observed in our study.

In the present study, there were no significant differences in many factors when comparing patient backgrounds between the $\mathrm{H}$ and $\mathrm{N}$ groups (Table 2). In particular, there was no significant difference between the two groups with respect to the presence or absence of metastasis to other organs at hepatectomy or with respect to tumour markers, which are considered to be strongly correlated with long-term prognosis. Furthermore, BMI, which was reported to be a poor prognostic factor by several investigative groups [23, 24], tended to be lower in the $\mathrm{N}$ group, which was defined as not having sarcopenia, than in the $\mathrm{H}$ group. Therefore, BMI was not considered useful in predicting the long-term prognosis of patients in this study. In the studies examining the clinical significance of IMAC in patients with several diseases $[9,10,12,13]$, BMI was reported to be higher in sarcopenia groups as defined by IMAC. BMI is widely used as an indicator of nutritional status because it is convenient to measure in daily clinical practice. However, evaluating BMI might not be useful for assessing nutritional status in patients with CRLM. Recently, the concept of sarcopenic obesity has been proposed. It has been suggested that sarcopenic obesity is a poor prognostic factor in several malignant diseases $[25,26]$. In the present study, BMI was higher in the $\mathrm{H}$ group than in the $\mathrm{N}$ group; thus, the proportion of body fat might also be higher in the $\mathrm{H}$ group, suggesting that a high IMAC may be an index of sarcopenic obesity. Therefore, IMAC might be useful in assessing sarcopenic obesity.

PMI, which we used as a quantitative index of skeletal muscle, was not associated with short- or long-term outcomes. Therefore, we do not consider PMI to be an adequate index to measure the sarcopenic condition of patients. In previous studies about liver disease [9-11], PMI was reported to be insufficient as a prognostic predictor; therefore, we thought that this tendency might be reflected in our findings. To assess this possibility, we 
therefore focused on muscle quality, in terms of IMAC. When PMI is derived from the area of skeletal muscle, it might reflect both fat and muscle content. Thus, it is possible that actual skeletal muscle mass cannot be obtained by measuring the area of skeletal muscle. In contrast, IMAC is calculated as the ratio of skeletal muscle to subcutaneous adipose tissue, using CT values. Therefore, IMAC may reflect the sarcopenic state of a patient more accurately than measurements of skeletal muscle area. The negative impacts of skeletal muscle fat deposition include muscle weakness and associated restricted movement $[27,28]$; this pathology may contribute to the high incidence of postoperative complications. Moreover, postoperative complications have been reported as long-term prognostic factors in several malignancies [29, 30]. In our study, the incidence of postoperative complications was higher in the sarcopenic $\mathrm{H}$ group than in the $\mathrm{N}$ group. This may have contributed to the poor long-term prognosis in the $\mathrm{H}$ group.

Although sarcopenia has been reported previously as a prognostic factor in various malignancies [3-8], its mechanism has not been fully elucidated. Skeletal muscle is maintained by the balance between protein degradation and synthesis [31]. However, in sarcopenic patients, muscle catabolism is increased [32, 33], presumably due to chronic inflammation [34-37]. The cause of chronic inflammation is attributed to the presence of cancer cells [38, 39], obesity [40-45], adipocytokines secreted from adipocytes [40-45], and the suppression of cancer immunity [39]. In the present study, BMI was higher in the $\mathrm{H}$ group than in the $\mathrm{N}$ group; therefore, the proportion of body fat might also be considered higher in the $\mathrm{H}$ group. Accordingly, it is possible that skeletal muscle catabolism had progressed in the sarcopenic $\mathrm{H}$ group. Moreover, in the $\mathrm{H}$ group, antitumour immunity may have been reduced for the reasons described above [39], thereby affecting the longterm prognosis of the patients. It is possible that cancer, and chronic inflammation caused by obesity, might cause fat deposition in skeletal muscle.

There was no significant difference between the two groups regarding the site of primary metastasis. A systemic decline in cancer immune function might have contributed to the increased recurrence rate. However, chronic inflammation is only one of several mechanisms related to the cause of sarcopenia. Further studies are needed to elucidate the pathological mechanisms of sarcopenia.

To improve sarcopenic conditions, nutritional interventions, such as amino acid supplementation, have been reported to be effective [27, 46]. In the future, prospective studies are needed to establish the specific nutritional interventions which may improve the postoperative prognosis of patients with CRLM and high
IMAC. Moreover, as we did not measure the serum adipocytokine level, or the visceral and subcutaneous fat area, we intend to conduct further research focusing on adipocytokines and fat volumes.

The present study had several limitations. One limitation relates to the number of patients included. Although there have been some reports on the association between IMAC and malignancy [11-13], our study used fewer patients than those studies. We excluded 26 patients without umbilicus-level CT data. Further, because of differences in surgical invasiveness and treatment policies, we also excluded patients who underwent two-stage hepatectomy or prior hepatectomy. However, we plan to continue collecting patient data. A second limitation of our study is whether the IMAC and PMI cut-off values that we used were appropriate. At present, there is no consensus on the appropriate IMAC and PMI values of healthy individuals. In our study, sarcopenia was defined using ROC curve-derived cut-off values. The ROC curve is considered a reasonable way to determine cut-off values [9]. However, we hope that IMAC and PMI will be used to define sarcopenia more commonly in the future.

A third limitation is the extended observation period. Excluding four cases for which follow-up was not possible, 13 of the patients had their surgery less than 5 years ago. For these few patients, postoperative observation will continue in order gain additional insight regarding the usefulness of IMAC as a prognostic factor. A fourth limitation is the heterogeneity of the patient background factors. We included cases of metastasis to various other organs at the time of hepatectomy, and there was no standardized adjuvant chemotherapy and treatment. Twenty patients with metastasis to other organs were included in this study. However, it has been reported that the prognosis after hepatectomy for patients with resectable or controllable extrahepatic metastasis is not inferior to that of patients with liver metastasis alone [47, 48]. Moreover, because there was no significant difference in the proportion of patients with other-organ metastases between the high-IMAC group and the normal-IMAC group, we included cases with metastasis to other organs.

It has been reported that adjuvant chemotherapy after hepatectomy for CRLM does not improve prognosis [49]. We did not establish clear administration criteria for adjuvant chemotherapy in our study. Moreover, in this study, we did not actively conduct neoadjuvant chemotherapy. The feasibility of using neoadjuvant chemotherapy for CRLM is still controversial [50-52]. Although neoadjuvant chemotherapy for resectable CRLM is recommended in the National Comprehensive Cancer Network (NCCN) guidelines [53], hepatectomy without neoadjuvant chemotherapy is recommended in 
the Japanese guidelines [54, 55]. Therefore, we did not actively conduct neoadjuvant chemotherapy for resectable CRLM. In principle, hepatectomy was performed for patients with fewer than four metastases, without using neoadjuvant chemotherapy. Patients with four or more metastases in both lobes, major vessel invasion, or extrahepatic metastases were treated with neoadjuvant chemotherapy before hepatectomy. We hope that the feasibility of IMAC will be demonstrated in the group of patients who underwent neoadjuvant chemotherapy for resectable CRLM. We found no significant difference in the proportion of patients who received perioperative chemotherapy in groups $\mathrm{H}$ and $\mathrm{N}$; thus, perioperative adjuvant chemotherapy was not considered to be a prognostic factor in the present study.

\section{Conclusions}

In conclusion, high IMAC impacted the postoperative short- and long-term prognosis of patients with CRLM. Preoperative IMAC might be considered as a new selection criterion for hepatectomy in CRLM patients.

\section{Abbreviations}

ASA score: American Society of Anesthesiologists classification score; BMI: Body mass index; CA19-9: Carbohydrate antigen 19-9;

CEA: Carcinoembryonic antigen; CRC: Colorectal cancer; CRLM: Colorectal liver metastasis; CT: Computed tomography; CUSA: Cavitron Ultrasonic Surgical Aspirator; IMAC: Intramuscular adipose tissue content; IMAT: Intramuscular adipose tissue; mGPS: Modified Glasgow prognostic score; NASH: Non-alcoholic steatohepatitis; OS: Overall survival; PMI: Psoas muscle index; PNI: Prognostic nutritional index; RFS: Recurrence-free survival; ROC curve: Receiver operating characteristic curve; ROI: Region of interest
\end{abstract}

\section{Acknowledgements}

We would like to thank Editage (www.editage.com) for English language editing.

\section{Authors' contributions}

$\mathrm{HN}$ contributed to the manuscript conception and participated in the surgery, literature retrieval, and writing. YS and TK participated in the surgery, patient data collection, and manuscript drafting and writing. $\mathrm{HA}$ and $\mathrm{El}$ drafted the manuscript. The authors read and approved the final manuscript.

\section{Funding}

No specific funding was obtained for this study.

\section{Availability of data and materials}

The datasets used and analysed in this study are not publicly available (to maintain privacy) but are available from the corresponding author on reasonable request.

\section{Ethics approval and consent to participate}

This retrospective study was approved by the ethics committee of Yokohama City University. The ethics approval, consent to use medical records and electronic data, and consent for publication were obtained from the ethics committee of Yokohama City University.

\section{Consent for publication}

Not applicable.

\section{Competing interests}

The authors declare that they have no competing interests.
Received: 26 September 2019 Accepted: 19 March 2020

Published online: 07 April 2020

\section{References}

1. Dodson S, Baracos VE, Jatoi A, Evans WJ, Cella D, Dalton JT, et al. Muscle wasting in cancer cachexia: clinical implications, diagnosis, and emerging treatment strategies. Annu Rev Med. 2011;62:265-79.

2. Pedersen BK, Febbraio MA. Muscles, exercise and obesity: skeletal muscle as a secretory organ. Nat Rev Endocrinol. 2012;8(8):457-65.

3. Reisinger KW, Bosmans JW, Uittenbogaart M, Alsoumali A, Poeze M, Sosef $\mathrm{MN}$, et al. Loss of skeletal muscle mass during neoadjuvant chemoradiotherapy predicts postoperative mortality in esophageal cancer surgery. Ann Surg Oncol. 2015;22(13):4445-52.

4. Paireder M, Asari R, Kristo I, Rieder E, Tamandl D, Ba-Ssalamah A, et al. Impact of sarcopenia on outcome in patients with esophageal resection following neoadjuvant chemotherapy for esophageal cancer. Eur J Surg Oncol. 2017;43(2):478-84.

5. Rutten IJ, van Dijk DP, Kruitwagen RF, Beets-Tan RG, Olde Damink SW, van Gorp T. Loss of skeletal muscle during neoadjuvant chemotherapy is related to decreased survival in ovarian cancer patients. J Cachexia Sarcopenia Muscle. 2016;7(4):458-66.

6. Zhuang $C L$, Huang DD, Pang WY, Zhou CJ, Wang SL, Lou N, et al. Sarcopenia is an independent predictor of severe postoperative complications and long-term survival after radical gastrectomy for gastric cancer: analysis from a large-scale cohort. Medicine (Baltimore). 2016;95(13):e3164.

7. Joglekar S, Asghar A, Mott SL, Johnson BE, Button AM, Clark E, et al. Sarcopenia is an independent predictor of complications following pancreatectomy for adenocarcinoma. J Surg Oncol. 2014;111(6):771-5.

8. Prado CM, Lieffers JR, McCargar LJ, Reiman T, Sawyer MB, Martin L, et al. Prevalence and clinical implications of sarcopenic obesity in patients with solid tumours of the respiratory and gastrointestinal tracts: a populationbased study. Lancet Oncol. 2008;9(7):629-35.

9. Hamaguchi Y, Kaido T, Okumura S, Fujimoto Y, Ogawa K, Mori A, et al. Impact of quality as well as quantity of skeletal muscle on outcomes after liver transplantation. Liver Transpl. 2014;20(11):1413-9.

10. Kitajima $Y$, Hyogo H, Sumida $Y$, Eguchi $Y$, Ono N, Kuwashiro T, et al. Severity of non-alcoholic steatohepatitis is associated with substitution of adipose tissue in skeletal muscle. J Gastroenterol Hepatol. 2013;28(9):1507-14.

11. Hamaguchi Y, Kaido T, Okumura S, Kobayashi A, Shirai H, Yagi S, et al. Impact of skeletal muscle mass index, intramuscular adipose tissue content, and visceral to subcutaneous adipose tissue area ratio on early mortality of living donor liver transplantation. Transplantation. 2017;101(3):565-74.

12. Hamaguchi Y, Kaido T, Okumura S, Ito T, Fujimoto Y, Ogawa K, et al. Preoperative intramuscular adipose tissue content is a novel prognostic predictor after hepatectomy for hepatocellular carcinoma. J Hepatobiliary Pancreat Sci. 2015;22(6):475-85.

13. Kobayashi A, Kaido T, Hamaguchi Y, Okumura S, Shirai H, Kamo N, et al. Impact of visceral adiposity as well as sarcopenic factors on outcomes in patients undergoing liver resection for colorectal liver metastases. World J Surg. 2018;42(4):1180-91.

14. Torre LA, Bray F, Siegel RL, Ferlay J, Lortet-Tieulent J, Jemal A. Global cancer statistics, 2012. CA Cancer J Clin. 2015;65(2):87-108.

15. van der Geest LG, Lam-Boer J, Koopman M, Verhoef C, Elferink MA, de Wilt $J \mathrm{H}$. Nationwide trends in incidence, treatment and survival of colorectal cancer patients with synchronous metastases. Clin Exp Metastasis. 2015; 32(5):457-65.

16. Leporrier J, Maurel J, Chiche L, Bara S, Segol P, Launoy G. A populationbased study of the incidence, management and prognosis of hepatic metastases from colorectal cancer. Br J Surg. 2006;93(4):465-74.

17. Kopetz S, Chang GJ, Overman MJ, Eng C, Sargent DJ, Larson DW, et al. Improved survival in metastatic colorectal cancer is associated with adoption of hepatic resection and improved chemotherapy. J Clin Oncol. 2009;27(22):3677-83.

18. Bismuth $H$, Adam R, Levi F, Farabos C, Waechter F, Castaing D, et al. Resection of nonresectable liver metastases from colorectal cancer after neoadjuvant chemotherapy. Ann Surg. 1996;224(4):509-22.

19. Onodera T, Goseki N, Kosaki G. Prognostic nutritional index in gastrointestinal surgery of malnourished cancer patients. Nihon Geka Gakkai Zasshi. 1984;85(9):1001-5 [In Japanese]. 
20. Clavien PA, Sanabria JR, Strasberg SM. Proposed classification of complications of surgery with examples of utility in cholecystectomy. Surgery. 1992;111(5):518-26.

21. Clavien PA, Barkun J, de Oliviera ML, Vauthey JN, Dindo D, Schulick RD, et al. The Clavien-Dindo classification of surgical complications: five-year experience. Ann Surg. 2009;250(2):187-96.

22. Chen S, Nie RC, OuYang LY, Li YF, Xiang J, Zhou ZW, et al. Body mass index (BMI) may be a prognostic factor for gastric cancer with peritoneal dissemination. World J Surg Oncol. 2017;15(1):52

23. Miyazaki T, Sakai M, Sohda M, Tanaka N, Yokobori T, Motegi Y, et al. Prognostic significance of inflammatory and nutritional parameters in patients with esophageal cancer. Anticancer Res. 2016;36(12):6557-62.

24. Pecorelli N, Capretti G, Sandini M, Damascelli A, Cristel G, De Cobelli F, et al. Impact of sarcopenic obesity on failure to rescue from major complications following pancreaticoduodenectomy for cancer: results from a multicenter study. Ann Surg Oncol. 2018;25(1):308-17.

25. Okumura S, Kaido T, Hamaguchi Y, Kobayashi A, Shirai H, Yao S, et al. Visceral adiposity and sarcopenic visceral obesity are associated with poor prognosis after resection of pancreatic cancer. Ann Surg Oncol. 2017;24(12): 3732-40.

26. Goodpaster BH, Park SW, Harris TB, Kritchevsky SB, Nevitt M, Schwartz AV, et al. The loss of skeletal muscle strength, mass, and quality in older adults: the health, aging and body composition study. J Gerontol A Biol Sci Med Sci. 2006:61(10):1059-64.

27. Delmonico MJ, Harris TB, Visser M, Park SW, Conroy MB, Velasquez-Mieyer $P$, et al. Longitudinal study of muscle strength, quality, and adipose tissue infiltration. Am J Clin Nutr. 2009;90(6):1579-85.

28. $\mathrm{Xu} L N, X u$ YY, Gao DW. Impact of operative and perioperative factors on the long-term prognosis of primary liver cancer patients undergoing hepatectomy. J Huazhong Univ Sci Technolog Med Sci. 2016;36(4):523-8.

29. Okamura Y, Takeda S, Fujii T, Sugimoto H, Nomoto S, Nakao A. Prognostic significance of postoperative complications after hepatectomy for hepatocellular carcinoma. J Surg Oncol. 2011;104(7):814-21.

30. Dalamaga M. Interplay of adipokines and myokines in cance pathophysiology: emerging therapeutic implications. World J Exp Med 2013:3(3):26-33.

31. Sharma D, Wang J, Fu PP, Nagalingam A, Mells J, Handy J, et al. Adiponectin antagonizes the oncogenic actions of leptin in hepatocellular carcinogenesis. Hepatology. 2010;52(5):1713-22.

32. Phillips SM, Glover El, Rennie MJ. Alterations of protein turnover underlying disuse atrophy in human skeletal muscle. J Appl Physiol. 2009;107(3):645-54.

33. Volpi E, Sheffield-Moore M, Rasmussen BB, Wolfe RR. Basal muscle amino acid kinetics and protein synthesis in healthy young and older men. JAMA. 2001;286(10):1206-12.

34. D'Antona G, Nisoli E. mTOR signaling as a target of amino acid treatment of the age-related sarcopenia. Interdiscip Top Gerontol. 2010;37:115-41.

35. Schaap LA, Pluijm SM, Deeg DJ, Visser M. Inflammatory markers and loss of muscle mass (sarcopenia) and strength. Am J Med. 2006;119(6):526.e9-17.

36. Schaap LA, Pluijm SM, Deeg DJ, Harris TB, Kritchevsky SB, Newman AB, et al. Higher inflammatory marker levels in older persons: associations with 5-year change in muscle mass and muscle strength. J Gerontol A Biol Sci Med Sci. 2009;64(11):1183-9.

37. Granic A, Davies K, Martin-Ruiz C, Jagger C, Kirkwood TBL, von Zglinicki T, et al. Grip strength and inflammatory biomarker profiles in very old adults. Age Ageing. 2017;46(6):976-82.

38. Coussens LM, Werb Z. Inflammation and cancer. Nature. 2002;420(6917): 860-7.

39. Coussens LM, Zitvogel L, Palucka AK. Neutralizing tumor-promoting chronic inflammation: a magic bullet? Science. 2013;339(6117):286-91.

40. Vincent HK, Raiser SN, Vincent KR. The aging musculoskeletal system and obesityrelated considerations with exercise. Ageing Res Rev. 2012;11(3):361-73.

41. Sakuma K, Yamaguchi A. Sarcopenic obesity and endocrinal adaptation with age. Int J Endocrinol. 2013;204164.

42. Schrager MA, Metter EJ, Simonsick E, Ble A, Bandinelli S, Lauretani F, et al. Sarcopenic obesity and inflammation in the InCHIANTI study. J Appl Physiol. 2007:102(3):919-25.

43. Fujisawa $T$, Endo $H$, Tomimoto A, Sugiyama M, Takahashi $H$, Saito $S$, et al. Adiponectin suppresses colorectal carcinogenesis under the high-fat diet condition. Gut. 2008;57(11):1531-8.

44. Endo $H$, Hosono K, Uchiyama $T$, Sakai E, Sugiyama M, Takahashi H, et al. Leptin acts as a growth factor for colorectal tumours at stages subsequent to tumour initiation in murine colon carcinogenesis. Gut. 2011;60(10):1363-71.

45. Harada H, Kai H, Shibata R, Niiyama H, Nishiyama Y, Murohara T, et al. New diagnostic index for sarcopenia in patients with cardiovascular diseases. PLoS One. 2017;12(5):e0178123.

46. Bassi C, Marchegiani G, Dervenis C, Sarr M, Abu Hilal M, Adham M, et al. The 2016 update of the International Study Group (ISGPS) definition and grading of postoperative pancreatic fistula: 11 years after. Surgery. 2017; 161(3):584-91.

47. Nojiri K, Tanaka K, Nagano Y, Ueda M, Matsui K, Ota M, et al. Efficacy of surgery for lung metastases from colorectal cancer synchronous to or following that for liver metastases. Anticancer Res. 2011;31(3):1049-54.

48. Lee WS, Yun HR, Yun SH, Chun HK, Lee WY, Kim SJ, et al. Treatment outcomes of hepatic and pulmonary metastases from colorectal carcinoma. J Gastroenterol Hepatol. 2008:23(8 Pt 2):e367-72.

49. Nordlinger B, Sorbye H, Glimelius B, Poston GJ, Schlag PM, Rougier P, et al. Perioperative FOLFOX4 chemotherapy and surgery versus surgery alone for resectable liver metastases from colorectal cancer (EORTC 40983): long-term results of a randomised, controlled, phase 3 trial. Lancet Oncol. 2013;14(12): 1208-15.

50. Mukai T, Uehara K, Goto H, Hiramatsu K, Kobayashi S, Sakamoto E, et al. Phase II trial of neoadjuvant chemotherapy with S-1 and oxaliplatin plus bevacizumab for colorectal liver metastasis (N-SOG 05 trial). Jpn J Clin Oncol. 2017:47(7):597-603. https://doi.org/10.1093/jjco/hyx048.

51. Bonney GK, Coldham C, Adam R, Kaiser G, Barroso E, Capussotti L, et al. Role of neoadjuvant chemotherapy in resectable synchronous colorectal liver metastasis; an international multi-center data analysis using LiverMetSurvey. J Surg Oncol. 2015;111(6):716-24. https://doi.org/10.1002/jso.23899.

52. Schreckenbach T, Malkomes P, Bechstein WO, Woeste G, Schnitzbauer AA, Ulrich F. The clinical relevance of the Fong and the Nordlinger scores in the era of effective neoadjuvant chemotherapy for colorectal liver metastasis. Surg Today. 2015;45(12):1527-34. https://doi.org/10.1007/s00595-014-1108-9.

53. Provenzale D, Gupta S, Ahnen DJ, Markowitz AJ, Chung DC, Mayer RJ, et al. NCCN guidelines insights: colorectal cancer screening, version 1.2018. J Natl Compr Cancer Netw. 2018;16(8):939-49.

54. Hashiguchi Y, Muro K, Saito Y, Ito Y, Ajioka Y, Hamaguchi T, et al. Japanese Society for Cancer of the Colon and Rectum (JSCCR) guidelines 2019 for the treatment of colorectal cancer. Int J Clin Oncol. 2019. https://doi.org/10. 1007/s10147-019-01485-z.

55. Toiyama Y, Miki C, Inoue Y, Tanaka K, Mohri Y, Kusunoki M. Evaluation of an inflammation-based prognostic score for the identification of patients requiring postoperative adjuvant chemotherapy for stage II colorectal cancer. Exp Ther Med. 2011;2(1):95-101. https://www.ncbi.nlm.nih.gov/pmc/ articles/PMC3440627/.

\section{Publisher's Note}

Springer Nature remains neutral with regard to jurisdictional claims in published maps and institutional affiliations.

Ready to submit your research? Choose BMC and benefit from

- fast, convenient online submission

- thorough peer review by experienced researchers in your field

- rapid publication on acceptance

- support for research data, including large and complex data types

- gold Open Access which fosters wider collaboration and increased citations

- maximum visibility for your research: over $100 \mathrm{M}$ website views per year

At $\mathrm{BMC}$, research is always in progress.

Learn more biomedcentral.com/submissions 